Portland State University

PDXScholar

$12-28-2020$

\title{
To What Extent Do Local Nursing Home Prescribing Patterns Relate to Psychotropic Prescribing in Assisted Living?
}

\author{
Kali Thomas \\ Brown University \\ Christopher J. Wretman \\ University of North Carolina \\ Philip D. Sloane \\ University of North Carolina \\ Paula Carder \\ Portland State University, carderp@pdx.edu \\ Lindsay Schwartz \\ American Health Care Association/National Center for Assisted Living \\ Follow this and additional works at: https://pdxscholar.library.pdx.edu/aging_pub

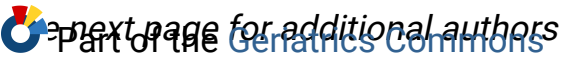 \\ Let us know how access to this document benefits you.
}

\section{Citation Details}

Thomas, K. S., Wretman, C. J., Sloane, P. D., Carder, P., Schwartz, L., Beeber, A. S., \& Zimmerman, S. (2020). To What Extent Do Local Nursing Home Prescribing Patterns Relate to Psychotropic Prescribing in Assisted Living? Journal of the American Medical Directors Association, S1525861020310239. https://doi.org/10.1016/j.jamda.2020.11.037

This Post-Print is brought to you for free and open access. It has been accepted for inclusion in Institute on Aging Publications by an authorized administrator of PDXScholar. Please contact us if we can make this document more accessible: pdxscholar@pdx.edu. 


\section{Authors}

Kali Thomas, Christopher J. Wretman, Philip D. Sloane, Paula Carder, Lindsay Schwartz, Anna S. Beeber, and Sheryl Zimmerman 
Original Study

\title{
To What Extent Do Local Nursing Home Prescribing Patterns Relate to Psychotropic Prescribing in Assisted Living?
}

\author{
Kali S. Thomas $\mathrm{PhD}^{\mathrm{a}, \mathrm{b}, *}$, Christopher J. Wretman $\mathrm{PhD}^{\mathrm{c}}$, Philip D. Sloane MD, MPH ${ }^{\mathrm{c}}$, \\ Paula Carder $\mathrm{PhD}^{\mathrm{d}}$, Lindsay Schwartz $\mathrm{PhD}^{\mathrm{e}}$, Anna S. Beeber PhD, RN, FAAN ${ }^{\mathrm{c}}$, \\ Sheryl Zimmerman $\mathrm{PhD}^{\mathrm{c}}$ \\ ${ }^{a}$ Department of Health Services, Policy, and Practice, Brown University School of Public Health, Providence, RI, USA \\ ${ }^{\mathrm{b}}$ Center of Innovation in Long-Term Services and Supports, U.S. Department of Veterans Affairs Medical Center, Providence, RI, USA \\ ${ }^{\mathrm{c}}$ The Cecil G. Sheps Center for Health Services Research; School of Social Work; University of North Carolina at Chapel Hill, NC, USA \\ d OHSU-PSU School of Public Health, Portland State University, Portland, OR, USA \\ ${ }^{\mathrm{e}}$ Center for Health Policy Evaluation in Long-Term Care; American Health Care Association/National Center for Assisted Living, Washington, DC, USA
}

\section{Keywords:}

Assisted living

geographic variation

long-term care

antipsychotics

prescribing

\begin{abstract}
A B S T R A C T
Objective: In nursing homes (NHs), psychoactive medication use has received notable attention, but less is known about prescribing in assisted living (AL). This study examined how antipsychotic and antianxiety medication prescribing in AL compares with NHs.

Design: Observational, cross-sectional AL data linked to publicly reported $\mathrm{NH}$ measures.

Setting and Participants: Random sample of 250 AL communities and the full sample of 3371 NHs in 7 states.

Methods: We calculated the percentage of residents receiving antipsychotics and antianxiety medications. For each AL community, we calculated the distance to NHs in the state. Linear models estimated the relationship between AL prescribing and that of the closest and farthest $5 \mathrm{NHs}$, adjusting for AL characteristics and state fixed effects.

Results: The prescribing rate of potentially inappropriate antipsychotics (i.e., excluding for persons with recorded schizophrenia and Tourette syndrome) and of antianxiety medications (excluding for those on hospice) in AL was $15 \%$ and $21 \%$, respectively. Unadjusted mean antipsychotic prescribing rates were nominally higher in AL than NHs (14.8\% vs $14.6 \% ; P=.056)$, whereas mean antianxiety prescribing was nominally lower in $\mathrm{AL}(21.2 \%$ vs $22.6 \% ; P=.032)$. In adjusted analyses, AL rates of antipsychotic use were not associated with $\mathrm{NH}$ rates. However, being affiliated with an $\mathrm{NH}$ was associated with a lower rate of antipsychotic use $[\mathrm{b}=-0.03 ; 95 \%$ confidence interval $(\mathrm{CI})-0.50$ to $-0.001 ; P=.043]$, whereas antianxiety rates were associated with neighboring NHs' prescribing rates $(b=0.43 ; 95 \%$ CI $0.16-0.70$; $P=.002$ ).

Conclusions and Implications: This study suggests reducing antipsychotic medication use in NHs may influence AL practices in a way not accounted for by local NH patterns. And, because antianxiety medications have not been the focus of national campaigns, they may be more subject to local prescribing behaviors. It seems advantageous to consider prescribing in AL when efforts are implemented to change $\mathrm{NH}$ prescribing, as there seems to be related influence whether by affiliation or region.
\end{abstract}

Published by Elsevier Inc. on behalf of AMDA - The Society for Post-Acute and Long-Term Care Medicine.
A large proportion of long-term care residents in nursing homes (NHs) and assisted living (AL) are diagnosed with Alzheimer disease

\footnotetext{
The authors declare no conflicts of interest.

This work was supported by the National Institute on Aging (\#AG050602 to SZ) and the U.S. Department of Veterans Affairs (CDA 14-422 to KST).

* Address correspondence to Kali S. Thomas, PhD, MA, Brown University School of Public Health, Box G-S121(6), Providence, RI 02912.

E-mail address: Kali_Thomas@brown.edu (K.S. Thomas).
}

and related dementias, many of whom exhibit behaviors that convey distress (historically referred to as behavioral and psychological symptoms of dementia). ${ }^{1,2}$ As many as $97 \%$ of persons living with dementia exhibit at least 1 such behavior, most often apathy, depression, irritability, agitation, and anxiety. ${ }^{3-5}$ Often, these behaviors are difficult to treat. Although the Food and Drug Administration (FDA) has approved a number of medications for the treatment of severe mental illness (ie, schizophrenia, psychosis, bipolar disorder, 
serious/major depression), there are currently no FDA-approved drugs to treat behavioral expressions of persons with dementia. Nonetheless, off-label use of psychoactive medications has been prevalent in $\mathrm{NHs}$, despite a large body of evidence suggesting that their use, and especially that of antipsychotics, increases the risk of side effects that adversely affect health, safety, and quality of life (eg, falls, cardiovascular events, infections, mortality). ${ }^{6-16}$

To address the high rates of off-label antipsychotic use among $\mathrm{NH}$ residents, the Centers for Medicare and Medicaid Services (CMS) launched the National Partnership to Improve Dementia Care in Nursing Homes in 2012. ${ }^{17}$ Through the Partnership, CMS engaged stakeholders (eg, $\mathrm{NH}$ chains, quality improvement organizations, advocacy groups), created and disseminated educational resources to $\mathrm{NH}$ staff and administrators, began publicly reporting antipsychotic use as a quality measure, provided additional guidance and training to state surveyors to identify inappropriate use, and increased enforcement through issuing Civil Monetary Penalties to NHs that had unnecessarily high rates of antipsychotic use. Reports suggest potentially inappropriate antipsychotic use in NHs decreased following the implementation of the Partnership and its activities. ${ }^{18,19}$

However, unlike NHs that are federally regulated, states regulate $\mathrm{AL}$; therefore, the efforts of CMS to reduce antipsychotic use have not extended to these residences, despite approximately $42 \%$ of residents in AL living with at least moderate cognitive impairment or a diagnosis of dementia ${ }^{1,16}$ and an estimated $30 \%$ to $40 \%$ receiving some form of antipsychotic medication. ${ }^{20,21}$ Thus, it is useful to compare AL prescribing patterns with those in NHs to determine if there is a need for state-level initiatives to reduce antipsychotic medication use in this important sector of long-term care.

When examining antipsychotic prescribing, it is important to consider geography, given the notable geographic variation in antipsychotic prescribing in $\mathrm{NHs}^{22,23}$ and AL. For example, one systematic review $^{22}$ suggested that $\mathrm{NHs}$ in metropolitan areas and those located in the south or northeast had higher rates of antipsychotic medication use than their counterparts. An expert panel attributed varying rates to differences in organizational cultures, state laws, training, hiring patterns, staffing levels, staffing mix, and provider practice patterns. There is also indication of geographic variation in prescribing in AL. Data from the 2010 National Survey of Residential Care Facilities found that the percentage of residents who display a behavioral "symptom" and "have a medication prescribed to control behavior" ranged from $50.9 \%$ in the 3 Middle Atlantic states (New Jersey, New York, and Pennsylvania) to $62.4 \%$ in the 4 West South Central states (Arkansas, Louisiana, Oklahoma, and Texas) (Derived from the National Survey of Residential Care Facilities, 2010 [unpublished results]).

The fact that both NHs and AL communities are home to residents with dementia, and that both settings use psychoactive medications to treat residents' behaviors, begs the question as to what extent local practice patterns influence prescribing across both settings. There has been no study of the concurrent prescribing in geographically proximate NHs and AL communities; if patterns of potential influence were detected, it is possible that policy and other initiatives promoted in NHs will influence AL practices. Therefore, the objectives of this study were to examine how prescribing of potentially inappropriate antipsychotics and of antianxiety medications in AL compares with that in $\mathrm{NHs}$, and to understand the extent to which prescribing is similar in $\mathrm{NHs}$ and $\mathrm{AL}$ communities in the same geographic region.

\section{Methods}

Sample

A random sample of $250 \mathrm{AL}$ communities was recruited from the 7 states in the census divisions that reported the lowest and highest antipsychotic prescribing in AL (Derived from the National Survey of
Residential Care Facilities, 2010 [unpublished results]): Arkansas, Louisiana, New Jersey, New York, Oklahoma, Pennsylvania, and Texas. Data were collected in 2 regions of each state, each containing clusters of contiguous counties that together represented the entire state on 8 demographic variables used in previous work (ie, per capita income, percentage of population below the poverty level, percentage of population nonwhite, unemployment rate, percentage of the population age 65 and over; number of primary care physicians, and hospital and $\mathrm{NH}$ beds per individual age 65 and older). ${ }^{24}$ In Arkansas, Oklahoma, Louisiana, and New Jersey, the 2 regions comprised the entire state. Eligible AL communities $(\mathrm{N}=1624)$ were actively licensed providers of residential, non-nursing long-term care with a census of more than 4 residents, and with a primary population older than 65 years. After randomly sampling communities proportionate to size, 35 to 40 communities were recruited in each state. AL administrators received an individualized letter of invitation to participate, followed by a telephone call. All participating sites received a $\$ 100$ gift card.

The sample of NHs was drawn from publicly available data reported on the Nursing Home Compare website in the same 7 states $(\mathrm{N}=3371)$.

\section{Data Collection and Measures}

In AL communities, on-site visits were conducted in one-half of the communities in each state in the first year, and the second half of $\mathrm{AL}$ communities were visited in the second year to avoid effects from the passing of time (October 2016 to November 2018). Data related to antipsychotic and antianxiety prescribing were abstracted from all residents' medication administration records, and residents' charts were used to identify residents' diagnoses; data collectors were trained for chart abstraction and had a mean interrater reliability level of $\mathrm{k}=0.93$ for medication data and $\mathrm{k}=0.89$ for other chart data. In addition, the AL administrator provided information as to whether the community was affiliated with another AL community or with a $\mathrm{NH}$, whether they had dementia-specific beds, and if their case-mix related to schizophrenia, dementia, and receiving Medicaid. Data collectors were able to access resident charts via a Health Insurance Portability and Accountability Act (HIPAA) waiver, administrators provided informed consent, and all procedures were approved by the Institutional Review Board of the University of North Carolina, Chapel Hill.

Data for NHs were downloaded from Nursing Home Compare, using the long-stay quality measure for the quarter that coincided with the time the data were collected in their closest AL community, specifically the "percentage of long-stay residents who got an antipsychotic medication" and the "percentage of long-stay residents who got an antianxiety or hypnotic medication." The antipsychotic percentages created by CMS exclude residents with schizophrenia, Huntington disease, and Tourette syndrome from the denominator because these diagnoses typically result in appropriate prescribing of antipsychotics. The antianxiety/hypnotic percentages created by CMS exclude residents receiving hospice or with a 6-month prognosis from the denominator.

Similar to the specifications for the CMS NH long-stay quality measures, we calculated an AL community-level measure of the percentage of residents currently receiving an antipsychotic (both first-generation/typical and second-generation/atypical; 18 different medications), excluding residents with schizophrenia and Tourette syndrome from the denominator; data were not available regarding Huntington disease, but its prevalence is known to be low in $\mathrm{NHs}^{25}$ and so expected to be similarly low in AL. We also followed CMS' specifications and calculated an AL community-level measure of the percentage of residents who received an antianxiety or hypnotic medication (both benzodiazepine and nonbenzodiazepine; 20 different medications), excluding residents receiving hospice 
from the denominator. See Supplementary Table 1 for a list of medications.

\section{Analysis}

All AL analyses use weights based on probability proportional to bed size, whereby data on AL residents sampled were scaled to represent the entirety of residents within each of the 250 communities. Details regarding weighting procedures are reported in the Appendix.

Geographic analyses began by obtaining longitude and latitude coordinates for each of the $250 \mathrm{AL}$ communities and $3371 \mathrm{NHs}$ to a precision level of $<10.0$ kilometers using data from the OpenCage Geocoder API (see Supplementary Tables 2 and 3). ${ }^{26}$ AL communities were then geographically matched with $\mathrm{NHs}$ based on ellipsoidal distance as per Vincenty's equations. ${ }^{27}$

AL community-level prescribing rates were compared descriptively with the average rates for the nearest 5 and farthest $5 \mathrm{NHs}$, as well as the $\mathrm{NH}$ state average. In the text and tables, the AL community being compared is referred to as the "source" community. The statistical significance of these comparisons was assessed with 1-sample (AL vs NH state average) and 2-sample paired (AL vs NHs) Wilcoxon signed-rank tests.

Finally, the collective rates of the nearest and farthest $\mathrm{NH}$ rates were analyzed for their association with the source AL antipsychotic and antianxiety rates adjusting for select community characteristics (ie, affiliation, dementia beds, and 3 measures of resident case-mix: percentage of residents with schizophrenia, percentage of residents with dementia, and percentage of residents receiving Medicaid). We used adjusted linear models with state fixed effects and empirical sandwich standard errors. All analyses were conducted in Stata 16.1 (StataCorp, College Station, TX) with statistical significance set at $P<.05$.

\section{Results}

A total of $743 \mathrm{AL}$ communities were invited to participate, 354 (48\%) of which refused; the recruitment status of 130 (17\%) remained pending at the conclusion of the study, and data collection in $9(1 \%)$ sites could not be completed. Nonparticipating and participating sites did not differ by size $(P=.43)$. Medication and chart data were collected for a sample of 5777 residents in these 250 communities; all $250 \mathrm{AL}$ administrators participated in interviews.

As shown in Table 1 , the AL communities were roughly equally distributed across states; $41 \%$ were affiliated with another AL community (ie, member of a chain), $29 \%$ were affiliated with a $\mathrm{NH}$, and $46 \%$ had some dementia beds (eg, a memory care unit). In total, $5 \%$ of residents had a diagnosis of schizophrenia, $41 \%$ had a diagnosis of dementia, and $7 \%$ were receiving hospice. Overall, the prescribing rate of antipsychotics (excluding for persons with schizophrenia and Tourette syndrome) and antianxiety drugs (excluding for persons on hospice) was $15 \%$ and $21 \%$, respectively.

As displayed in Table 2, overall unadjusted rates of potentially inappropriate antipsychotic prescribing were nominally higher in AL communities than NHs (14.8\% vs $14.6 \% ; P=.056$ ), and ranged from $11.9 \%$ in New Jersey ( $10.2 \%$ for all NHs) to $18.7 \%$ in Texas ( $15.7 \%$ for all NHs). Conversely, prescribing of antianxiety medications in Alabama was nominally lower than the $\mathrm{NH}$ average in the 7 states (21.2\% vs $22.6 \% ; P=.032$ ), ranging from $16.0 \%$ in Louisiana ( $25.3 \%$ for all $\mathrm{NHs}$ ) to $25.3 \%$ in Oklahoma ( $28.2 \%$ for all NHs). The unadjusted rates of prescribing in AL did not differ significantly from the 5 nearest or farthest NHs on aggregate, but significant within-state differences were observed.

In the adjusted analysis (see Table 3), AL rates of potentially inappropriate antipsychotic use were not associated with rates in the nearest or farthest NHs. However, being affiliated with a NH was associated with a lower rate of potentially inappropriate antipsychotic use $(b=-0.03 ; 95 \% \mathrm{CI}-0.50$ to $-0.001 ; P=.043)$, meaning that $\mathrm{AL}$ communities that were affiliated with a $\mathrm{NH}$ evidenced 0.03 percentage points less antipsychotic prescribing. In terms of antianxiety medications, AL rates were not associated with the average of the 5 farthest NHs' rates; however, AL rates of antianxiety medication use were significantly associated with neighboring $\mathrm{NHs}$ ' rates of prescribing, whereby a $1 \%$ increase in the average nearby NHs' rates was associated with a 0.43 percentage point increase in an AL community's rate of antianxiety medication prescribing $(\mathrm{b}=.43 ; 95 \% \mathrm{CI} .16$ to 70 ; $P=.002)$. Also, AL prescribing was significantly related to case-mix in 4 of 6 comparisons (eg, higher antipsychotic prescribing associated with a higher proportion of residents with dementia).

\section{Discussion}

This first of its kind study examining potentially inappropriate antipsychotic and antianxiety prescribing in a sample of $250 \mathrm{AL}$ communities and more than $3000 \mathrm{NHs}$ had 3 main findings. First, rates of antipsychotic and antianxiety prescribing in AL vary by state. Second, potentially inappropriate antipsychotic prescribing in AL is not associated with local $\mathrm{NH}$ prescribing patterns, but antianxiety/ hypnotic medication use is positively associated with local $\mathrm{NH}$ prescribing rates. Third, antipsychotic prescribing rates are lower among AL communities affiliated with a $\mathrm{NH}$, but the same relationship does not exist for antianxiety prescribing in AL. The following paragraphs expound on these observations.

There was a close to 7 percentage point spread in medication use rates in AL communities across the states. Texas was among the top 2 states in its rates of prescribing of both types of medications, and Louisiana had the lowest (tied with New Jersey for antipsychotic prescribing). The variation in rates of prescribing may be a function of the underlying population in these communities, or the regulations pertaining to medication administration and the care of residents with dementia and mental health diagnoses. There is some suggestion that both contribute to the observed difference. For example, Texas and

Table 1

Assisted Living Community Characteristics $(\mathrm{N}=250)$

\begin{tabular}{lc}
\hline Characteristics & $\mathrm{n}(\%)$ or Mean (SD) \\
\hline State & $35(14.0)$ \\
Arkansas & $27(10.8)$ \\
Louisiana & $37(14.8)$ \\
New Jersey & $38(15.2)$ \\
New York & $37(14.8)$ \\
Oklahoma & $40(16.0)$ \\
Pennsylvania & $36(14.4)$ \\
Texas & \\
Affiliation & $101(40.9)$ \\
Affiliated with other assisted living community & $71(28.7)$ \\
Affiliated with other nursing home & $115(46.0)$ \\
Has dementia beds & \\
Resident case-mix* & $5.2(12.0)$ \\
Percentage of residents with schizophrenia & $41.0(26.1)$ \\
Percentage of residents with dementia & $10.1(24.3)$ \\
Percentage of residents receiving Medicaid & $6.6(9.7)$ \\
Percentage of residents receiving hospice & \\
Psychotropic prescribing & $14.8(11.3)$ \\
Antipsychotic rate & \\
Antianxiety rate & $21.2(13.1)$ \\
\hline
\end{tabular}

Sources $=$ administrator interview and resident charts.

*Percent based on resident-level weighted counts of individual residents/ community.

'Denominator excludes residents diagnosed with schizophrenia or Tourette syndrome.

${ }^{\ddagger}$ Denominator excludes residents receiving hospice. 
Table 2

Assisted Living (AL) and Matched Nursing Home (NH) Antipsychotic and Antianxiety Prescribing Rates, by Medication Category and State

\begin{tabular}{|c|c|c|c|c|c|c|c|}
\hline \multirow[t]{2}{*}{ Medication Category and State } & \multirow{2}{*}{$\begin{array}{l}\text { A. Source } \\
\frac{\text { AL Communities }}{\% \text { Mean }(\mathrm{SD})}\end{array}$} & \multirow{2}{*}{$\begin{array}{l}\text { B. Average of Nearest } \\
5 \text { NHs } \\
\% \text { Mean }(\mathrm{SD})\end{array}$} & \multirow{2}{*}{$\begin{array}{l}\text { C. Average of Farthest } \\
5 \mathrm{NHs} \\
\% \text { Mean }(\mathrm{SD})\end{array}$} & \multirow{2}{*}{$\begin{array}{l}\text { D. All State } \\
\text { NHs } \\
\% \text { Mean }\end{array}$} & \multicolumn{3}{|c|}{$P$ Values for Differences } \\
\hline & & & & & A v. B & A v. C & A v. D* \\
\hline \multicolumn{8}{|l|}{ Antipsychotic medications } \\
\hline All states & $14.8(11.3)$ & $14.2(4.3)$ & $12.5(3.2)$ & 14.6 & .36 & .33 & .056 \\
\hline Arkansas $(\mathrm{n}=35)$ & $14.9(12.2)$ & $14.4(3.2)$ & $10.7(3.9)$ & 14.3 & .59 & .038 & .49 \\
\hline Louisiana $(\mathrm{n}=27)$ & $12.0(7.6)$ & $16.4(3.9)$ & $15.6(3.3)$ & 16.5 & .019 & .002 & .008 \\
\hline New Jersey $(n=37)$ & $11.9(7.3)$ & $9.1(2.5)$ & $9.8(0.8)$ & 10.2 & .056 & .93 & .69 \\
\hline New York $(\mathrm{n}=38)$ & $15.1(12.4)$ & $11.8(2.5)$ & $10.7(0.9)$ & 11.7 & .37 & .002 & .28 \\
\hline Oklahoma $(\mathrm{n}=37)$ & $14.9(11.3)$ & $16.0(4.6)$ & $13.4(3.2)$ & 18.9 & .23 & .58 & .005 \\
\hline Pennsylvania $(\mathrm{n}=40)$ & $15.6(12.2)$ & $16.0(3.0)$ & $15.1(1.3)$ & 15.6 & .15 & .86 & .29 \\
\hline Texas $(\mathrm{n}=36)$ & 18.7 (12.9) & $16.4(4.2)$ & $13.0(1.9)$ & 15.7 & .62 & .99 & .41 \\
\hline \multicolumn{8}{|l|}{ Antianxiety medications } \\
\hline All states & $21.2(13.1)$ & $21.7(6.7)$ & $21.9(5.1)$ & 22.6 & .14 & .27 & .032 \\
\hline Arkansas $(\mathrm{n}=35)$ & $19.6(14.1)$ & $25.1(9.0)$ & $20.8(4.7)$ & 24.9 & .16 & .52 & .036 \\
\hline Louisiana $(\mathrm{n}=27)$ & $16.0(11.3)$ & $23.6(7.1)$ & $19.6(4.2)$ & 25.3 & .11 & .10 & .001 \\
\hline New Jersey $(n=37)$ & $19.8(12.0)$ & $19.6(5.0)$ & $23.2(5.6)$ & 19.7 & .24 & .14 & .99 \\
\hline New York $(\mathrm{n}=38)$ & $22.2(11.4)$ & $14.8(4.7)$ & $15.6(2.4)$ & 14.3 & .14 & .005 & $<.001$ \\
\hline Oklahoma $(\mathrm{n}=37)$ & $25.3(13.7)$ & $26.0(4.8)$ & $26.9(4.0)$ & 28.2 & .97 & .43 & .16 \\
\hline Pennsylvania $(n=40)$ & $19.7(11.9)$ & $19.9(4.4)$ & $23.9(1.6)$ & 21.7 & .31 & .050 & .28 \\
\hline Texas $(\mathrm{n}=36)$ & $24.7(15.1)$ & $24.1(3.5)$ & $22.3(3.9)$ & 25.5 & .031 & .48 & .63 \\
\hline
\end{tabular}

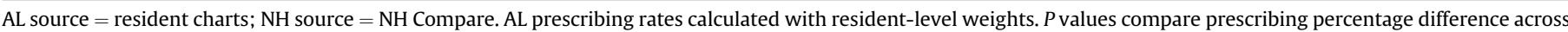
sites using Wilcoxon signed-rank test (2-sided).

*One-sample test. Communities matched by ellipsoidal distance based on Vincenty's equations using coordinates from OpenCage Geocoder.

New Jersey states with the highest prevalence of AL residents with dementia. ${ }^{28}$ In addition, Texas, New Jersey, and Louisiana's AL regulations are the only among the 7 in this study that specifically refer to the use of "psychoactive" drugs: Texas and Louisiana specifically prohibit the use of "chemical restraints," defined as "drugs administered for the purposes of discipline or convenience and are not required to treat the resident's medical symptoms." Further, Texas requires staff of dementia care units to complete training on common psychotropic medications and their side effects. New Jersey requires residents who are administered "scheduled central nervous system agents" to be assessed by a registered nurse. The other 4 states' AL regulations are silent regarding the use of psychoactive medications. However, despite Texas's more robust regulations pertaining to psychoactive medication use, its rates of potentially inappropriate antipsychotic and antianxiety prescribing are among the highest in our sample. Research examining state differences in the populations served, processes of care, and regulations influencing prescribing patterns in $\mathrm{AL}$ is needed to better understand the state variation observed. For example, in 2012, New Jersey implemented a voluntary quality program that rewards AL for meeting quality benchmarks, including off-label use of antipsychotics. ${ }^{29}$

Interestingly, antipsychotic prescribing in AL was not associated with antipsychotic prescribing in local NHs in the adjusted models, whereas antianxiety medication use in AL was significantly associated with antianxiety use in local NHs. It is possible that because antianxiety/hypnotic medications have not been the focus of national campaigns to reduce their use in NHs, these medications are more likely to be subject to local practice patterns and prescribing behaviors. Previous literature suggests that the quality of prescribing for older adults varies substantially among local markets. ${ }^{30,31}$ Our

Table 3

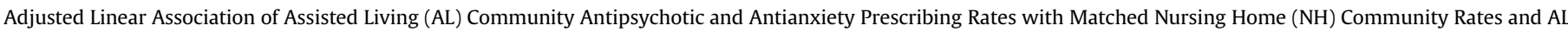
Characteristics

\begin{tabular}{|c|c|c|c|c|}
\hline \multirow[t]{2}{*}{ Prescribing Rates and Characteristics } & \multicolumn{2}{|c|}{$\begin{array}{l}\text { Antipsychotic Prescribing Rate* } \\
\mathrm{n}=246\end{array}$} & \multicolumn{2}{|c|}{$\begin{array}{l}\text { Antianxiety Prescribing Rate } \\
\mathrm{n}=246\end{array}$} \\
\hline & $\beta(95 \% \mathrm{CI})$ & $P$ & $\beta(95 \% \mathrm{CI})$ & $P$ \\
\hline \multicolumn{5}{|l|}{ Matched prescribing rates (\%) } \\
\hline Average of nearest $5 \mathrm{NHs}$ & -0.19 ( -0.46 to 0.09$)$ & .19 & 0.43 (0.16 to 0.70$)$ & .002 \\
\hline Average of farthest $5 \mathrm{NHs}$ & $-0.17(-0.57$ to 0.22$)$ & .39 & $-0.20(-0.59$ to 0.19$)$ & .32 \\
\hline \multicolumn{5}{|l|}{ Affiliation (reference $=$ No) } \\
\hline Affiliated with another AL community & $0.01(-0.01$ to 0.03$)$ & .44 & $0.01(-0.02$ to 0.04$)$ & .60 \\
\hline Affiliated with an $\mathrm{NH}$ & $-0.03(-0.05$ to -0.001$)$ & .043 & $-0.02(-0.06$ to 0.01$)$ & .23 \\
\hline Has dementia beds (reference $=$ No) & $0.003(-0.02$ to 0.03$)$ & .82 & $-0.005(-0.05$ to 0.04$)$ & .83 \\
\hline \multicolumn{5}{|l|}{ Resident case-mix (\%) } \\
\hline Percentage of residents with schizophrenia & $0.14(0.01$ to 0.28$)$ & .038 & $0.12(-0.01$ to 0.25$)$ & .078 \\
\hline Percentage of residents with dementia & $0.31(0.25$ to 0.37$)$ & $<.001$ & $0.17(0.07$ to 0.26$)$ & $<.001$ \\
\hline Percentage of residents receiving Medicaid & 0.07 (0.01 to 0.12$)$ & .018 & $0.08(-0.0005$ to 0.16$)$ & .051 \\
\hline
\end{tabular}

$\mathrm{CI}$, confidence interval.

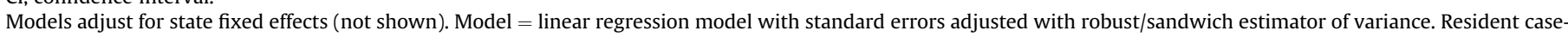

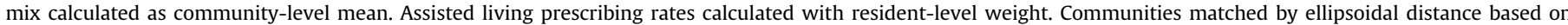
Vincenty's equations using coordinates from OpenCage Geocoder.

*Denominator excludes residents diagnosed with schizophrenia or Tourette syndrome.

'Denominator excludes residents receiving hospice.

Includes schizophrenia and related disorders therein. 
research suggests that this variation likely extends to long-term care settings, and that to the extent there is cause to promote new prescribing practices, they consider both AL and NHs.

$\mathrm{NH}$ affiliation was associated with decreased use of potentially inappropriate antipsychotic prescribing in AL, but not use of antianxiety/hypnotics. This finding may suggest that the increased focus on reducing antipsychotic medication use that has occurred in NHs has spilled over to affiliated AL communities, and changed provider practice in a way that is not accounted for by geography or proximity. The same pattern has been observed in NHs that are members of a chain, ${ }^{32,33}$ suggesting that chain membership may reflect a higher degree of corporate standardization and oversight that is more salient to how medications are used in long-term care settings than local physician prescribing patterns.

In addition, AL settings with a higher share of residents enrolled in Medicaid have higher rates of potentially inappropriate antipsychotic and of antianxiety medication use. A similar pattern has been observed in NHs: lower resourced NHs, or those with higher rates of Medicaid-financed residents and lower rates of Medicare-financed residents, have higher rates of potentially inappropriate antipsychotic and/or antianxiety/hypnotic prescribing. ${ }^{34,35}$ Relatedly, AL settings with a higher proportion of residents with diagnoses of schizophrenia or dementia have higher rates of potentially inappropriate antipsychotic and antianxiety medication use; this, too, has been observed in the $\mathrm{NH}$ setting. ${ }^{33}$ Particular efforts to promote nonpharmacologic interventions ${ }^{12,36}$ to address behaviors associated with dementia in addition to training and resources to treat anxietyrelated symptoms may be warranted in settings that have large proportions of their residents enrolled in Medicaid or with diagnoses of schizophrenia or dementia.

There are important limitations of this study to note. First, findings are based on an AL sample in 7 states, purposefully selected based on presumed variability in prescribing. Given the state variability in prescribing seen among this small sample, prescribing rates in other states are expected to vary as well. Also, while we attempted to replicate the $\mathrm{NH}$ quality measures in $\mathrm{AL}$, which exclude Huntington disease for the antipsychotic measure and 6-month prognosis for the antianxiety measure, the AL dataset did not include Huntington disease or prognosis, and so they are included in the denominator for the AL measures. However, the prevalence of Huntington disease in NHs is $0.14 \%{ }^{25}$ and we expect AL to have similarly low rates, if not lower, and therefore to not affect the results. In addition, the case-mix of $\mathrm{AL}$ residents (ie, percentage of residents with schizophrenia, percentage of residents with dementia, and percentage of residents receiving Medicaid) was self-reported by AL administrators; therefore, it is possible that these estimates are not precise. Finally, although we would have liked to compare rates among AL communities based on their proximity to each other, the sample of 35 to 40 communities per state did not allow for valid comparisons based on distance.

\section{Conclusions and Implications}

This study observed that rates of potentially inappropriate antipsychotic medication use among AL communities in our sample was, on average, higher than NHs' prescribing rates in the same state. Further, these rates were unrelated to local $\mathrm{NH}$ prescribing rates, but were associated with $\mathrm{NH}$ affiliation, which may speak to spillover of federal NH efforts. Conversely, antianxiety medication prescribing was lower for AL communities in our sample than NHs in the state, and associated with local $\mathrm{NH}$ prescribing rates, which suggests that absent federal efforts, regional efforts may potentially reduce rates of prescribing. Taken together, these results suggest efforts to reduce offlabel psychotropic medication use in NHs may be adapted and used to change prescribing patterns in $\mathrm{AL}$.

\section{Acknowledgments}

The authors thank Stephanie J. Miller, MSW, for her expert project coordination. They also thank the staff, residents, and families who participate in the Collaborative Studies of Long-term Care, for their commitment to understanding and improving care in assisted living and nursing homes.

\section{References}

1. Zimmerman S, Sloane PD, Reed D. Dementia prevalence and care in assisted living. Health Aff (Millbank) 2014;33:658-666.

2. McCreedy E, Ogarek JA, Thomas KS, Mor V. The Minimum Data Set Agitated and Reactive Behavior Scale: measuring behaviors in nursing home residents with dementia. J Am Med Dir Assoc 2019;20:1548-1552.

3. Buhr GT, White HK. Difficult behaviors in long-term care patients with dementia. J Am Med Dir Assoc 2007;8(3 Suppl 2):e101-e113.

4. Peters ME, Rosenberg PB, Steinberg M, et al. Prevalence of neuropsychiatric symptoms in CIND and its subtypes: The Cache County Study. Am J Geriatr Psychiatry 2012;20:416-424.

5. Steinberg M, Shao H, Zandi P, et al. Point and 5-year period prevalence of neuropsychiatric symptoms in dementia: The Cache County Study. Int J Geriatr Psychiatry 2008;23:170-177.

6. Lapeyre-Mestre M. A review of adverse outcomes associated with psychoactive drug use in nursing home residents with dementia. Drugs Aging 2016;33: 865-888.

7. Kuehn BM. FDA warns antipsychotic drugs may be risky for elderly. JAMA $2005 ; 293: 2462$

8. Dorsey ER, Rabbani A, Gallagher SA, et al. Impact of FDA black box advisory on antipsychotic medication use. Arch Intern Med 2010;170:96-103.

9. Kuehn BM. FDA: Antipsychotics risky for elderly. JAMA 2008;300:379-380.

10. Kerns JW, Winter JD, Winter KM, et al. Primary care physician perspectives about antipsychotics and other medications for symptoms of dementia. J Am Board Fam Med 2018;31:9-21.

11. Maher AR, Theodore G. Summary of the comparative effectiveness review on off-label use of atypical antipsychotics. J Manag Care Pharm 2012;18(5 Suppl B):S1-S20.

12. Dyer SM, Harrison SL, Laver K, et al. An overview of systematic reviews of pharmacological and non-pharmacological interventions for the treatment of behavioral and psychological symptoms of dementia. Int Psychogeriatr 2018; 30:295-309.

13. Ma H, Huang Y, Cong Z, et al. The efficacy and safety of atypical antipsychotics for the treatment of dementia: A meta-analysis of randomized placebocontrolled trials. J Alzheimers Dis 2014;42:915-937.

14. Lonergan E, Luxenberg J, Colford J. Haloperidol for agitation in dementia. Cochrane Database Syst Rev 2002;2:CD002852.

15. Ballard C, Waite J. The effectiveness of atypical antipsychotics for the treatment of aggression and psychosis in Alzheimer's disease. Cochrane Database Syst Rev 2006:1:CD003476.

16. Harrison SL, Bradley C, Milte R, et al. Psychotropic medications in older people in residential care facilities and associations with quality of life: A crosssectional study. BMC Geriatr 2018;18:60.

17. Centers for Medicare and Medicaid Services. CMS announces partnership to improve dementia care in nursing homes. Available at: https://www.cms.gov/ newsroom/press-releases/cms-announces-partnership-improve-dementiacare-nursing-homes. Accessed March 23, 2016.

18. Maust DT, Kim HM, Chiang C, Kales HC. Association of the Centers for Medicare \& Medicaid Services' national partnership to improve dementia care with the use of antipsychotics and other psychotropics in long-term care in the United States from 2009 to 2014. JAMA Intern Med 2018;178:640-647.

19. Centers for Medicare and Medicaid Services. National partnership to improve dementia care in nursing homes. Available at: https:/www.cms.gov/files/ document/antipsychotic-medication-use-data-report-updated-01242020.pdf. Accessed July 6, 2020.

20. Larrayadieu A, Abellan van Kan G, Piau A, et al. Associated factors with antipsychotic use in assisted living facilities: A cross-sectional study of 4367 residents. Age Ageing 2011;40:368-375.

21. Kronhaus A, Fuller S, Zimmerman S, Reed D. Prevalence and medication management of dementia by a medical practice providing onsite care in assisted living. J Am Med Dir Assoc 2016;17:673.e9-673.e15.

22. Cioltan H, Alshehri S, Howe C, et al. Variation in use of antipsychotic medications in nursing homes in the United States: A systematic review. BMC Geriatr 2017;17:32.

23. Briesacher BA, Tjia J, Field T, et al. Antipsychotic use among nursing home residents. JAMA 2013;309:440-442.

24. Zimmerman S, Sloane PD, Eckert JK, et al. How good is assisted living? Findings and implications from an outcomes study. J Gerontol B Psychol Sci Soc Sci 2005;60:S195-S204.

25. Zarowitz BJ, O’Shea T, Nance M. Clinical, demographic, and pharmacologic features of nursing home residents with Huntington's disease. J Am Med Dir Assoc 2014;15:423-428. 
K.S. Thomas et al. / JAMDA $x x x(2020)$ 1-6

26. Zeigermann L. Opencacegeo: Stat module for geocoding. Available at: http:// fmwww.bc.edu/RePEc/bocode/o/opencagegeo.pdf. Accessed February 26, 2020.

27. Vincenty T. Direct and inverse solutions of geodesics on the ellipsoid with application of nested equations. Survey Review 1975;23:88-93.

28. Thomas KS, Zhang W, Cornell PY, et al. State variability in the prevalence and healthcare utilization of assisted living residents with dementia. J Am Geriatr Soc 2020;68:1504-1511.

29. State of New Jersey Department of Health. Health and senior services commissioner announces innovative partnership to improve quality in assisted living residences. NJ Health. Available at: https://www.nj.gov/health/news/ 2012/approved/20120210a.shtml. Accessed July 6, 2020.

30. Zhang Y, Baicker K, Newhouse JP. Geographic variation in the quality of prescribing. N Engl J Med 2010;363:1985-1988.

31. Zhang Y, Steinman MA, Kaplan CM. Geographic variation in outpatient antibiotic prescribing among older adults. Arch Intern Med 2012;172:1465-1471.
32. Castle NG, Hanlon JT, Handler SM. Results of a longitudinal analysis of national data to examine relationships between organizational and market characteristics and changes in antipsychotic prescribing in US nursing homes from 1996 through 2006. Am J Geriatr Pharmacother 2009;7:143-150.

33. Hughes CM, Lapane KL, Mor V. Influence of facility characteristics on use of antipsychotic medications in nursing homes. Med Care 2000;38:1164-1173.

34. Stevenson DG, Decker SL, Dwyer LL, et al. Antipsychotic and benzodiazepine use among nursing home residents: Findings from the 2004 National Nursing Home Survey. Am J Geriatr Psychiatry 2010;18:1078-1092.

35. Lucas JA, Chakravarty S, Bowblis JR, et al. Antipsychotic medication use in nursing homes: A proposed measure of quality. Int J Geriatr Psychiatry 2014; 29:1049-1061.

36. Richter T, Meyer G, Möhler R, Köpke S. Psychosocial interventions for reducing antipsychotic medication in care home residents. Cochrane Database Syst Rev 2012;12:CD008634. 


\section{Appendix}

\section{Addressing Behavior and Mood in Assisted Living}

Funded by the National Institute on Aging (R01 AG050602)

Sheryl Zimmerman, PhD, Principal Investigator

\section{Selection, Sampling, and Weighting Procedures}

\section{Study Overview}

The National Institute on Aging study entitled Addressing Behavior and Mood in Assisted Living (NIA R01AG050602) recruited a stratified random sample of 250 assisted living (AL) sites (ie, "communities") across 7 states to learn about care practices for residents with dementia.

Within each state, 2 geographic regions were identified that represent the entire state based on 8 variables used in other studies (see later in this appendix). Within each region, AL communities were randomly sampled using sampling probabilities proportionate to size. Within each AL community, data collection included chart abstraction, interviews, and observations. A few key additional details regarding data collection are as follows:

- A limited amount of data were collected by abstracting the charts of all AL residents (eg, demographic characteristics, residence on a dementia special care unit, use of medications): these are referred to as "short forms"

- A more in-depth chart abstract was completed for a stratified random sample of residents (ie, 4 strata defined by those with and without dementia, and those with and without antipsychotic prescriptions; data included medical, behavioral, and functional status, as well as other information): these are referred to as "long forms"

- A subsample of family members of residents with dementia who were receiving an antipsychotic medication participated in an interview

- All AL administrators and health care supervisors (ie, the staff member most knowledgeable about residents' health care and status, often referred to as a resident care coordinator or by another title) participated in an interview

- Data collectors completed an observational assessment of the physical structure of the AL community

As detailed later in this appendix, because these 250 communities were randomly sampled within regions, site-level probability weights can be used to scale up individual-level short-form data to the region level. For the subset of residents who were randomly sampled within communities, probability weights that are the product of individual-level weights and the aforesaid sitelevel weights can be used to scale up individuals' long-form data to the region level. Finally, using post-stratification weights to account for disproportionate coverage of beds in a state's regions, region-level data can be scaled up to the 2-region area within a state, which we call a super-region and which comprises the entire state in 4 states. In 3 states where the 2 selected regions do not provide complete coverage of the state, super-region-level data are nonetheless deemed to be representative of states because the 2 regions were selected to be representative of the state on key variables. Henceforth, we refer to super-regions as states.

\section{Selection of States and Regions}

The study focused on residents within AL sites within regions within states, meaning that individual-level resident data are multiply nested. In particular, the sampling design defines 14 regions as strata
(2 per state), randomly sampled sites (primary sampling units) within regions, and then samples individuals within sites.

States. To maximize expected variability in dementia care practices across states, states were chosen within 2 prespecified census areas representing the (1) lowest and (2) highest expected rates of "medication used to control resident behavior" based on data provided by the National Center for Health Statistics. These 2 areas were the "Middle Atlantic" and "West South Central," respectively. The Middle Atlantic area contains the 3 states of New Jersey, New York, and Pennsylvania, and the West South Central area contains the 4 states of Arkansas, Louisiana, Oklahoma, and Texas.

Regions. Regions were created within each of these 7 states from groups of contiguous counties. Counties were selected based on representativeness to the state on 8 variables used in previous work1: (1) per capita income, (2) percentage of population below the poverty level, (3) percentage of nonwhite population, (4) unemployment rate, (5) percentage of population aged $65+,(6)$ number of primary care physicians per individual aged $65+,(7)$ number of hospital beds per individual aged $65+$, and (8) number of nursing home beds per individual aged $65+$.

Two regions were purposively selected within each state for a total of 14 eligible regions. For 4 states (Arkansas, Louisiana, New Jersey, Oklahoma), the resultant regions represented the entirety of the states. For the other states (New York, Pennsylvania, Texas), regions represented only a portion of the state.

\section{Sampling and Site Weighting}

The general sampling strategy for sites was probability proportional to size random sampling using sites' total bed size. In this way, larger sites had a larger probability of being sampled. We define strata to be the regions $(\mathrm{N}=14)$. The primary sampling units are the AL sites selected within the regions.

Calculation of the site-level (ie, first-stage) weights begins by defining the total number of beds in the $h$-th region in the $s$-th state as

$M_{1 s h}=\sum_{i=1}^{N_{s h}} M_{1 s h i}$,

where $M_{1 s h i}=$ total number of licensed beds in the $i$-th site from the $h$-th region of the $s$-th state in 2014-2015, and $N_{s h}=$ number of sites in the $h$-th region of the $s$-th state. On a single draw with probability proportionate to size, the probability of selecting the $i$-th site in the $h$-th region in the $s$-th state is $M_{1 s h i} / M_{1 s h}$. Because we randomly select $n_{s h}$ sites from the $h$-th region in the $s$-th state, the probability that the $i$-th site is selected is

$n_{\text {sh }} M_{1 s h i} / M_{1 s h}$,

where $n_{s h}=20$ or $n_{s h}=40$ depending on the region and draw. Of the 250 community probabilities, a single probability that was $>1.0$ was winsorized down to exactly 1.0.

The first-stage weight is thus defined as the inverse of the probability of the site-level selection probability

$w_{1 s h i}=M_{1 s h} / n_{s h} M_{1 s h i}$

Of the 250 site-level weights, 4 (1.6\%) that were $>5.0$ times the mean were winsorized down to exactly 5.0 times the mean. This is the weight used to compute representative region-level statistics for site-level data or individual short-form measures. In other words, all individuals were included, meaning that no individuallevel selection probability or second-stage weight was necessary. For these measures, the individual-level weight is simply the firststage (ie, site-level) analytic weight. 
Sampling and Weighting of Individual Residents

For long-form measures, subsets of individuals were sampled within sites using stratified random sampling based on their probability of belonging to prespecified groups based on (1) dementia diagnosis status and (2) antipsychotic prescription status. Calculation of the individual-level (ie, second-stage) weights began by defining the probability of selecting an individual from the $j$-th group from the $i$-th site, given that the site is selected in the first-stage of sampling, as

$m_{\text {shij }} / M_{2 s h i j}$,

where $m_{\text {shij }}=$ the number of individuals sampled in the $j$-th group at the $i$-th site from the $h$-th region in the $s$-th state, and $M_{2 s h i j}=$ the total number of individuals in the $j$-th group at the $i$-th site from the $h$-th region of the $s$-th state based off of the actual number of records available at the time of data collection. The second-stage weight is thus defined as the inverse of the probability of the individual-level selection probability:

$w_{2 s h i j}=M_{2 s h i j} / m_{\text {shij }}$

Supplementary Table 1

Resident Antipsychotic and Antianxiety Medications

\begin{tabular}{|c|c|}
\hline Category and Medication Generic Name & Medication Brand Name(s) \\
\hline \multicolumn{2}{|l|}{ Antipsychotics } \\
\hline \multicolumn{2}{|l|}{ First-generation/Typical } \\
\hline Chlorpromazine & Largactil, Thorazine \\
\hline Fluphenazine & Permitil, Prolixin \\
\hline Haloperidol & Haldol, ABH (topical) \\
\hline Loxapine & Loxitane \\
\hline Perphenazine & Trilafon \\
\hline Thioridazine & Mellaril \\
\hline \multirow[t]{2}{*}{ Trifluoperazine } & Stelazine \\
\hline & Ativan Benadryl Haldol \\
\hline \multicolumn{2}{|l|}{ Second-generation/Atypical } \\
\hline Aripiprazole & Abilify \\
\hline Asenapine & Saphris \\
\hline Brexpiprazole & Rexulti \\
\hline Clozapine & Clozaril, FazaClo \\
\hline Lurasidone & Latuda \\
\hline Olanzapine & Zyprexa \\
\hline Paliperidone & Invega \\
\hline Quetiapine & Seroquel \\
\hline Risperidone & Risperdal \\
\hline Ziprasidone & Geodon \\
\hline \multicolumn{2}{|l|}{ Anxiolytics and hypnotics } \\
\hline \multicolumn{2}{|l|}{ Benzodiazepine anxiolytics } \\
\hline Alprazolam & Niravam, Xanax \\
\hline Chlordiazepoxide & Libritabs, Librium \\
\hline Clonazepam & Klonopin \\
\hline Clorazepate & Tranxene SD \\
\hline Diazepam & Valium \\
\hline Lorazepam & Ativan \\
\hline Oxazepam & Serax \\
\hline \multicolumn{2}{|l|}{ Nonbenzodiazepine anxiolytics } \\
\hline Buspirone & BuSpar \\
\hline Hydroxyzine & Atarax, Vistaril \\
\hline \multicolumn{2}{|l|}{ Benzodiazepine receptor agonist hypnotics } \\
\hline Estazolam & Prosom \\
\hline Eszopiclone & Lunesta \\
\hline Temazepam & Restoril \\
\hline Triazolam & Halcion \\
\hline Zaleplon & Sonata \\
\hline Zolpidem & Ambien \\
\hline \multicolumn{2}{|l|}{ Nonbenzodiazepine hypnotics } \\
\hline Diphenhydramine & Allermax, Benadryl \\
\hline Doxylamine & Nytol, Unisom \\
\hline Ramelteon & Rozerem \\
\hline Suvorexant & Belsomra \\
\hline Melatonin & Bio Melatonin, Sgard \\
\hline
\end{tabular}

The number of residents sampled in the $j$-th group at the $i$-th site from the $h$-th region in the $s$-th state is set to $m_{\text {shi } 1}=15$ (dementia diagnosis, antipsychotic prescription), $m_{\text {shi2 }}=15$ (dementia diagnosis, no antipsychotic prescription), $m_{\text {shi3 }}=15$ (no dementia diagnosis, antipsychotic prescription), and $m_{\text {shi4 }}=5$ (no dementia diagnosis, no antipsychotic prescription). When the number of residents of a particular group at the $i$-th site is less than the target sample number we set $m_{\text {shij }}=M_{2 s h i j}$.

When residents are sampled within sites, such as for long-form measures, the individual-level weight is thus defined as

$w_{\text {shij }}^{*}=w_{1 s h i} w_{2 s h i j}$,

which is the product of the first-stage and second-stage weights.

\section{Post-Stratification State-Level Estimates}

Scaling of the regions up to states requires a third component to combine region-level estimates. For producing state estimates, the region-level estimates $(n=2)$ for each state are combined with a weighting adjustment for the oversampling of 1 strata (ie, region) relative to the other with respect to the total number of beds per stratum.

First consider that the proportion of all beds in a state that are in the $h$-th region is $M_{2 s h} / M_{s}$, where $M_{s}$ is the total number of beds in the state. Formally, this value would be the total number of beds in the 2county region that defines the sampling frame in the $s$-th state given by $M_{s}=M_{2 s 1}+M_{2 s 2}$, where $M_{2 s h}=\sum_{i=1}^{N_{s h}} M_{2 s h i}$ and $M_{2 s h i}=\sum_{j=1}^{4} M_{2 s h i j}$.

The post-stratification weight for an individual from the $h$-th region in the $s$-th state is thus defined as the inverse of the probability of the region-level selection probability as

$w_{0 s h}=M_{s} / M_{2 s h}$,

and for individuals within states the individual-level weight is the product defined as

$w_{s h i j}^{* *}=w_{0 s h} w_{1 s h i} w_{2 s h i j}$,

where $w_{1 s h i}$ is the first-stage weight and $w_{2 s h i j}$ is the second-stage weight.

Supplementary Table 2

Community Geocode Characteristics

\begin{tabular}{lcl}
\hline Characteristics & Community Type & \\
\cline { 2 - 3 } & $\begin{array}{l}\text { Assisted Living } \\
\mathrm{n}=250 \\
\text { Frequency (\%) }\end{array}$ & $\begin{array}{l}\text { Nursing Home } \\
\mathrm{n}=906 \\
\text { Frequency }(\%)\end{array}$ \\
\hline Geocode accuracy & & \\
$\quad$ Street & $79(31.6)$ & $270(30.8)$ \\
$\quad$ Number & $171(68.4)$ & $627(69.2)$ \\
Geocode precision, km & $3(1.2)$ & $10(1.1)$ \\
$<10.0$ & $2(0.8)$ & $23(2.5)$ \\
$<7.5$ & $1(0.4)$ & $31(3.4)$ \\
$<5.0$ & $22(8.8)$ & $61(6.7)$ \\
$<1.0$ & $63(25.2)$ & $193(21.3)$ \\
$<0.5$ & $159(63.6)$ & $588(64.9)$ \\
$<0.25$ &
\end{tabular}

Geocode coordinates taken from OpenCage Geocoder. 
Supplementary Table 3

Assisted Living Community Distance from Matched Nursing Home, by State

\begin{tabular}{|c|c|c|c|c|c|c|}
\hline \multirow[t]{3}{*}{ States and Matching Scheme } & \multicolumn{6}{|c|}{ Distance in Kilometers from Community } \\
\hline & \multicolumn{2}{|c|}{ Nearest Match } & \multicolumn{2}{|c|}{ Nearest 5 Matches } & \multicolumn{2}{|c|}{ Farthest 5 Matches } \\
\hline & Range & Mean (SD) & Range & Mean (SD) & Range & Mean (SD) \\
\hline All states & $0.0-31.9$ & $2.4(3.9)$ & $0.6-52.8$ & $8.0(7.7)$ & $124.3-900.4$ & $426.1(192.6)$ \\
\hline Arkansas $(\mathrm{n}=35)$ & $0.0-19.3$ & $2.6(4.5)$ & $1.4-45.8$ & $12.9(10.9)$ & $246.1-427.6$ & $341.2(57.3)$ \\
\hline Louisiana $(\mathrm{n}=27)$ & $0.0-4.9$ & $1.5(1.4)$ & $1.8-19.8$ & $6.1(5.1)$ & $284.1-474.5$ & $388.6(62.6)$ \\
\hline New Jersey $(n=37)$ & $0.0-6.1$ & $1.6(1.6)$ & $1.5-11.4$ & $4.8(2.6)$ & $124.3-225.3$ & $170.8(30.5)$ \\
\hline New York $(\mathrm{n}=38)$ & $0.0-23.9$ & $2.6(4.3)$ & $0.6-26.2$ & $8.1(7.1)$ & $343.7-600.4$ & $479.6(69.1)$ \\
\hline Oklahoma $(\mathrm{n}=37)$ & $0.0-29.0$ & $2.7(5.0)$ & $2.0-32.3$ & $7.9(6.8)$ & $317.9-510.5$ & $377.9(49.8)$ \\
\hline Pennsylvania $(\mathrm{n}=40)$ & $0.0-11.5$ & $2.4(3.2)$ & $1.5-16.6$ & $6.7(4.1)$ & $260.6-462.6$ & $399.4(57.5)$ \\
\hline Texas $(n=36)$ & $0.1-31.9$ & $2.8(5.3)$ & $1.2-52.8$ & $9.1(11.0)$ & $740.8-900.4$ & $821.9(29.4)$ \\
\hline
\end{tabular}

Sites matched by ellipsoidal distance based on Vincenty's equations using coordinates taken from OpenCage Geocoder. 